\title{
Late Presentation of Ureterovesical Junction Obstruction after Submucosal Transurethral Injection of Dextranomer/Hyaluronic Acid Copolymer for Vesicoureteral Reflux
}

\author{
Edin Husaric, Amir Halilbasic, Nesad Hotic \\ Pediatric Clinic Tuzla, Department of Pediatric Surgery, Tuzla University Clinical Center, Tuzla, Bosnia and Herzegovina
}

Correspondence: edin.husaric@ukctuzla.ba; Tel./Fax.: + 385 303-740

Received: January 9, 2021, Accepted: May 12, 2021

\begin{abstract}
Objective - We report a case of late-presenting symptomatic ureterovesical junction obstruction after endoscopic treatment of low grade vesicoureteral reflux. Case report - A two-year old girl, with no other underlying conditions, underwent endoscopic Submucosal Transurethral Injection of one $\mathrm{ml}$ dextranomer/hyaluronic acid copolymer for grade three VUR on the right side. She recovered uneventfully and remained asymptomatic for one year, when she presented with right-side flank pain. Renal ultrasound showed hydronephrosis with calyceal dilatation and hydroureter. Ureterovesical junction obstruction caused by the bulking agent was suspected on MR urography. A large $2 \times 2 \mathrm{~cm}$ mass was found extravesically, clearly obstructing the ureter. After excision of the mass and reimplantation of the ureter, the hydronephrosis settled. Conclusion - However rare it is, ureterovesical obstruction may develop after endoscopic submucosal transurethral injection of dextranomer/hyaluronic acid copolymer. Long-term postoperative follow up may be necessary.
\end{abstract}

Key Words: Deflux - Ureterovesical Junction Obstruction.

\section{Introduction}

Endoscopic treatment of vesico ureteral reflux (VUR) by submucosus transureteral injection of a bulking agent (STING) was first described by Matouschek in 1981, and performed by Puri and O'Donnel in 1982 (1). One of the most commonly used bulking agents is a synthetic material, dextranomer/hyaluronic acid copolymer (2). Although success rates are up to $94 \%-98 \%$ depending the grade of VUR, complication rates remain very low (3). Obstruction of the urovesical junction caused by the bulking agent is rare $0.4 \%(4)-0.7 \%(5)$. The vast majority of the cases $(80 \%)$ present a few days after the injection and successfully managed with JJ stent insertion. Late-presenting cases are extremely rare.

\section{Case Report}

In December 2014, a two-year old girl presented with urinary tract infection, and was diagnosed with grade three VUR of the right-side. She underwent endoscopic treatment, where one ml Deflux gel was injected, at another institution. She recovered uneventfully and remained asymptomatic, and no hydronephrosis or VUR was demonstrated on her follow up on US and MCUG. After one year she presented with right-side flank pain. Renal US showed dilatation of the collecting system of the right kidney, as well as of the right ureter (Fig. 1). 


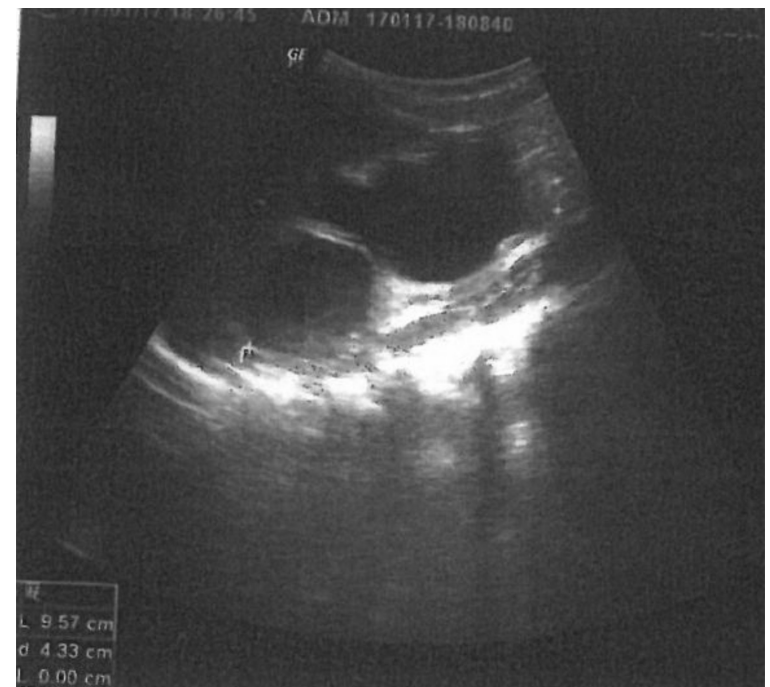

Fig. 1. Preoperative US.

Repeat MCUG did not show VUR. Tc-DMSA showed the function of the right kidney at $13 \%$. Obstruction of the right UVJ caused by the bulking agent was suspected on the MR urography (Fig. 2).

Extravesical ureteral reimplantation was planned. A $2 \times 2 \mathrm{~cm}$ large mass was found filling the ureter outside the bladder causing clear ureteral obstruction. (Fig. 3). Postoperative recovery was uneventful. Follow-up US after six months showed significant reduction of the uretero-hydronephrosis (Fig. 4).
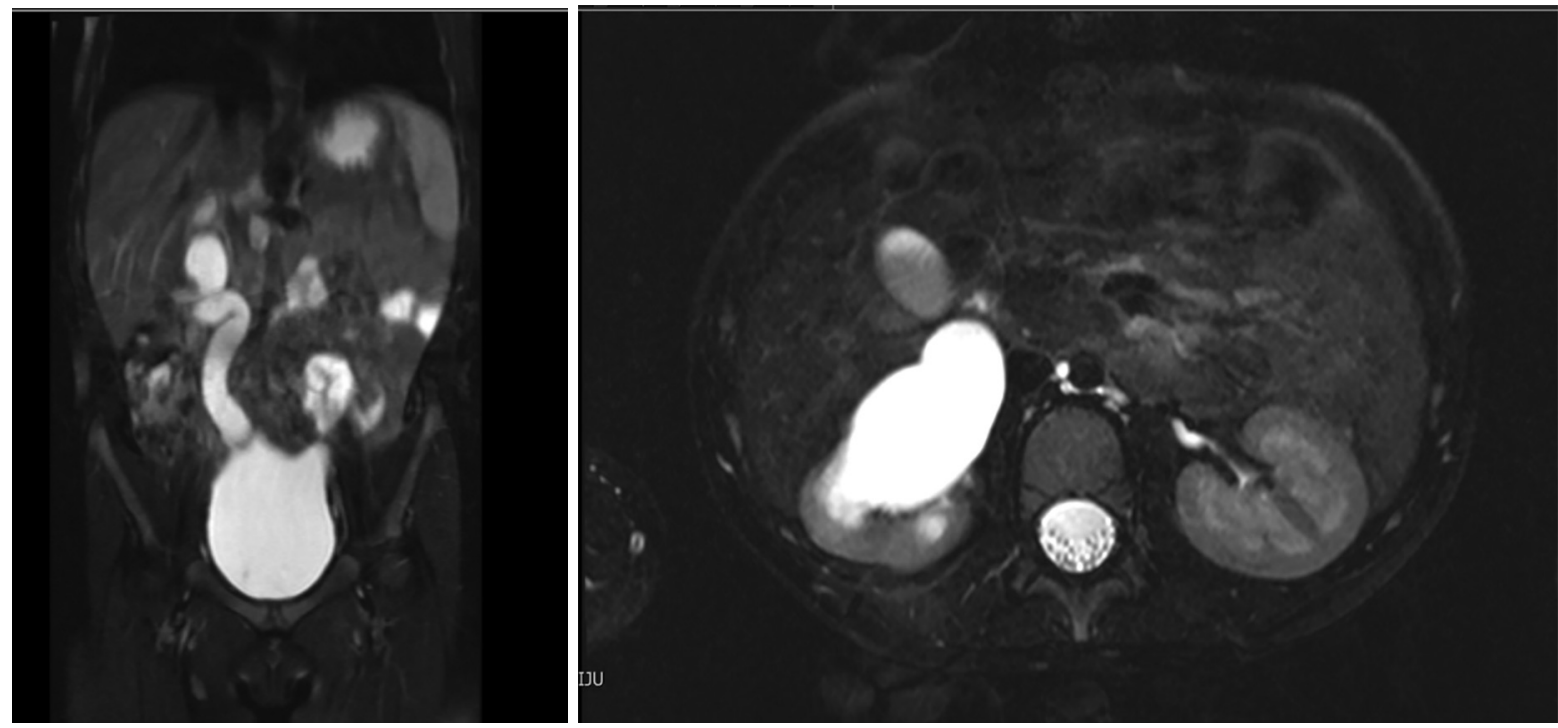

Fig. 2. MRI Urography.

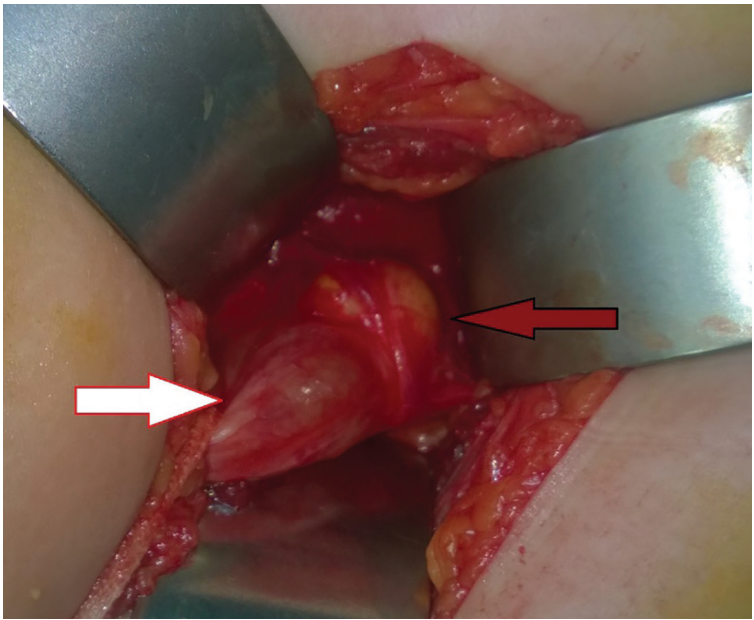

Fig. 3. White arrow the dilated right ureter, red arrow $2 \times 2$ $\mathrm{cm}$ large solid mass obstructing the ureter.

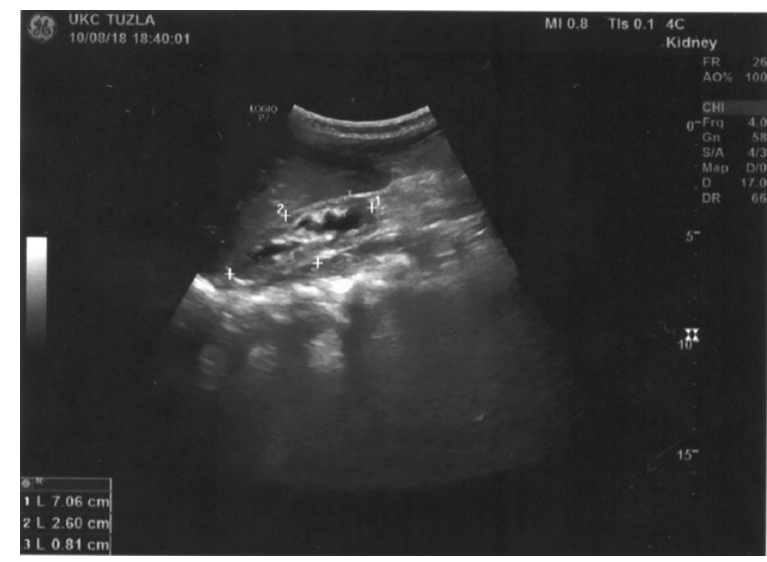

Fig. 4. Postoperative US 6 months after reimplantation, showing resolved hydronephrosis. 


\section{Discussion}

Twenty-five publications were identified that provide detailed information on 64 females and 32 males (age range: 7 months- 48 years) who developed ureterovesical junction obstruction (UVJO) after endoscopic treatment of VUR. There was some variation in the reported incidence of UVJO in relation to the different materials used: dextranomer/ hyaluronic acid Dx/HA (0.5\% - 6.1\%), polyacrylate polyalcohol PP $(1.1 \%-1.6 \%)$, polydimethylsiloxane PDMS $(2.5 \%-10.0 \%)$, calcium hydroxyapatite $\mathrm{CaHA}(1.0 \%)$, and polytetrafluoroethylene PTFE or collagen (6).

One study showed that with dextranomer/ hyaluronic acid the vast majority of obstructions presented early. Only very few publications were found regarding late presenting obstruction. In the latest case the obstruction was diagnosed 2 years after the intervention (7), However, in this case severe urinary tract infection presented one year after the injection. In our case, flank pain triggered an investigation one year after the injection. The symptoms and the severe progressive hydronephrosis with hydroureter, the lack of reflux on MCUG, and the fall in function on DMSA made the presence of an obstruction obvious, and no MAG3 scan was performed. MRU showed a mass at the UVJ responsible for the obstruction.

Grade V reflux, the presence of a beak sign on the preoperative MCUG, and inflamed bladder mucosa upon injection are significant independent risk factors leading to an obstruction (8). The type of bulking agent used and the injection volume tends to be associated with ureteral obstruction (5). Vandersteen et al. suggested that underlying conditions such as neuropathic bladder, dysfunctional voiding, an excess amount of bulking agent injected are also among the risks factors identified for postoperative UVJO. In our case, none of these underlying conditions were identified, however $1 \mathrm{ml}$ bulking agent was used to treat a relatively low grade VUR, where usually with $0.3-0.4 \mathrm{ml}$, an adequate antireflux effect can be achieved. This may have contributed to the obstruction. However, the fact that the obstruction did not develop rap- idly during the postoperative period suggests that other factors, such as late presenting calcification, migration of the bulking agent along the ureter or inflammatory granulation may have also played a role. The $2 \times 2 \mathrm{~cm}$ bulk found during the operation could not have come from $1 \mathrm{ml}$ Deflux alone.

Most cases of early ureteral obstruction reported in the literature were treated successfully with temporary double-J stenting, however late-presenting cases required open ureteral reimplantation $(9,10)$. In our case the large mass causing the obstruction was removed and the reimplantation was successful.

\section{Conclusion}

An increasing number of early and delayed ureteral obstructions are being reported following the STING procedure, although the incidence is still lower than the rate associated with open surgery $(9$, 10). Since delayed ureteral obstruction, resulting in silent loss of renal function, may occur as long as 4 or 5 years after the injection (11), long-term follow up seems to be reasonable.

\section{References}

1. O’Donnell B, Puri P. Treatment of vesicoureteric reflux by endoscopic injection of Teflon. Br Med J. (Clin Res Ed). 1984;289(6436):7-9.

2. Zyczkowski M, Prokopowicz G, Zajęcki W, Paradysz A. Complications following endoscopic treatment of vesicoureteric reflux with Deflux $\left({ }^{\oplus}\right)$ - two case studies. Cent European J Urol. 2012;65(4):230-31.

3. Chung JM, Park CS, Lee SD. Postoperative ureteral obstruction after endoscopic treatment for vesicoureteral reflux. Korean J Urol. 2015;56(7):533-9.

4. Vandersteen DR, Routh JC, Kirsch AJ, Scherz HC, Ritchey ML, Shapiro E, at al. Postoperative ureteral obstruction after subureteral injection of dextranomer/hyaluronic Acid copolymer. J Urol. 2006;176(4 Pt 1):1593-5.

5. Boudaoud N, Line A, Pons M, Lefebvre F, Bouche Pillon MA, Francois C, Poli Merol ML. Secondary megaureter: A rare complication of Deflux endoscopic management of vesicoureteral reflux in children. Arch Pediatr. 2017;24(3):249-53.

6. Friedmacher F, Puri P. Ureteral Obstruction After Endoscopic Treatment of Vesicoureteral Reflux: Does the 
Type of Injected Bulking Agent Matter? Curr Urol Rep. 2019;20(9):49.

7. Christen S, Mendoza M, Gobet R, Bode P, Weber D. Late ureteral obstruction after injection of dextranomer/ hyaluronic acid copolymer. Urology. 2014;83(4):9202.11212 .

8. Chertin B, Mele E, Kocherov S, Zilber S, Gerocarni Nappo S, Capozza N. What are the predictive factors leading to ureteral obstruction following endoscopic correction of VUR in the pediatric population? J Pediatr Urol. 2018(6):538.e1-538.e7.
9. Rubenwolf PC, Ebert AK, Ruemmele P, Rösch WH. Delayed-onset ureteral obstruction after endoscopic dextranomer/hyaluronic acid copolymer (Deflux) injection for treatment of vesicoureteral reflux in children: a case series. Urology. 2013;81(3):659-62.

10. Papagiannopoulos D, Rosoklija I, Cheng E, Yerkes E. Delayed Obstruction With Asymptomatic Loss of Renal Function After Dextranomer/Hyaluronic Acid Copolymer (Deflux) Injection for Vesicoureteral Reflux: A Close Look at a Disturbing Outcome. Urology. 2017;101:63-6.

11. Kim SW, Lee YS, Han SW. Endoscopic injection therapy. Investig Clin Urol. 2017;58(Suppl 1):38-45. 